\title{
Development of an Engineering Class Project InCorporating a Personal Vision of Sustainable DEVELOPMENT TEACHING
}

\author{
Ariane Pinsonnault, Stéphanie Muller, Annie Levasseur, and Réjean Samson \\ CIRAIG, Polytechnique Montreal \\ ariane.pinsonnault@polymtl.ca
}

\begin{abstract}
The decade 2005-2014 has been set by UNESCO as the United Nations decade of Education for Sustainable Development (SD) [1]. As graduate students of this decade, our vision of $S D$ teaching targets in engineering concerns the development of attitudes to assess projects and related impacts in a systemic way, the development of transversal skills, and the collaboration between experts from different fields to facilitate sustainable decisions. These assumptions can be linked to the qualities required by the Canadian Engineering Accreditation Board [2].

What kind of student exercises relies on all these assumptions? As teaching assistants (TA) in the class Environmental Design and Life Cycle Thinking (GCH2220-Polytechnique Montreal), we propose a possible answer. The main goals of this class are to familiarize students with the concepts of environmental design and life cycle thinking, as well as with different existing tools to apply these concepts. As TAs, we are in charge of a project that aims at providing students an opportunity to acquire practical aspects.
\end{abstract}

The subject of the project presented is the environmental redesign of coated paper production, and its main objectives are: to improve teamwork skills, to develop critical thinking when analyzing the results of an environmental assessment, and to develop skills to convince people within a company to adopt environmental solutions. In order to achieve these goals, the project was built on four main steps and students are evaluated through two reports and a poster presentation. Teams of four students were formed in order to mix students with different backgrounds (types of engineering programs, amount of credits completed) and obtain multidisciplinary teams. The project, the way it is presented in class, and its relevance for the students as future engineers are assessed through a survey in order to improve the exercise for the following classes.

Keywords: sustainable development, engineering pedagogy, TAs perspectives, soft skills, interdisciplinarity

\section{INTRODUCTION}

\subsection{Literature review}

Since 1987 and the Brundtland report, Sustainable development (SD) became a leitmotiv in discussions around development in different spheres [3,4]. Even if the Brundtland report and then the United Nations (UN) proposed a universal definition of SD, each person, each organisation has its own perception and definition. A recent paper published by Nature proposed an alternative for SD definition that no longer considers the three pillars (economy, society and environment) on a same level: "Development that meets the needs of the present while safeguarding Earth's life-support system, on which the welfare of current and future generations depends." [5]. According to this definition, a difficult target must be reached to guarantee a sustainable future, which will depend on the actions that will be taken and the decisions that will be made. In order to form people and future decision-makers, UNESCO has set the years 2005-2014 as the decade of education for SD, which aims to "Allows every human being to acquire the knowledge, skills, attitudes and values necessary to shape a sustainable future" [6]. In engineering faculties, as everywhere else, the concept of SD was added to course description and in the class, but it has been shown that changes in engineering education happen slowly, despite the fact that society evolves faster [1].

While traditionally, engineers have played a role according to development of technologies, the new role of engineers should focuses more on decision making by analyzing and synthesizing information about technological options to permit public debate, decision making and at the end, public acceptance of technologies [7]. At the same time, societal expectations and perceptions of the engineering profession are shifting, first because the profession is linked to some scandals (cf. the Charbonneau corruption inquiry that is happening now in Quebec) and has to answer them, and secondly 
because the problems they have to solve are more and more complex and linked to a globalized world. Engineers have roles and responsibilities within the society and some ask if technical skills are today the only skills require to fulfill these roles and responsibilities $[8,9]$. This new model makes sense since important decisions about technologies in sustainability will be taken in the future, for instance in energy production.

Otherwise, teamwork skills seem to be important in work performance since it's the second most important characteristic for recruiting employers [10]. The method of evaluation chosen in learning contexts plays an important role in teamwork success. Peer review for team evaluation, for instance, promote empowerment of students and develop teamwork skills by positively involving students in the evaluation of their learning [10].

The usual teaching approach used in science faculties implies mostly professors lecturing. This approach has been often criticized and a peer instruction has been developed as an alternative [11]. This new pedagogical method for knowledge transfer in science courses has been developed by university teachers and consists in involving each student in an active learning [11]. Transfer of information is assumed out of the classroom, as the assimilation of information is planned during class [12]. This method focuses on proposing problems with unknown solutions, but with known outcomes, which well represents real life problem solving. Problem solving usually proposed in classroom consists of problems with known procedures and unknown answers, which focuses on one good answer discouraging risk taking and creativity from students [12].

\subsection{Motivation}

Since autumn semester of 2006, the Environmental Design and Life Cycle Thinking course (GCH2220Polytechnique Montreal) aims to introduce environmental problems and the concept of sustainable development, as well as to raise awareness to various type of environmental conception to chemical and industrial engineering students. In other words, the course focuses on developing students' life-cycle thinking and students' abilities to identify environmental impacts of engineering projects. The course approach consists of lectures, assignments and a final project. In the last years, the final project proposed to teams of four students an application of the life-cycle methodology for the comparison of two products.

GCH2220 course gives pedagogical opportunities not often encountered in engineering: 1. A course developed around the sustainable development concept and its application in engineering projects; 2. A classroom consisting of engineering students from different programs and with different amounts of credits completed, and 3. A course proposing a final project in team.

\subsection{Problematic}

Given these opportunities within the class, our problematic is to develop a student exercise that relies on our own perception around SD teaching, without neglecting the application of technical aspects specific to the course GCH2220. As graduate students in environment and as engineers, we have developed our own perception of SD teaching targets in engineering (among others and inspired by others): 1.To assess a project and its related impacts on the environment and society development in a systematic way in agreement with a real life problem solving approach; 2.To develop the soft skills required for the new role of engineers and 3 . To collaborate between experts from different fields to facilitate sustainable decisions in a positive team dynamics.

\subsection{Solutions}

As teaching assistants (TA) in the course, we proposed a possible answer with the development of a project based on the environmental redesign of an industrial process. The development of the project is based on four main steps: 1. The critical review of an existing report, 2 . The identification of environmental hot spots, 3. The detailed proposition of a redesign based on the hot spots and 4 . The impact assessment of the redesign on environmental, economical and societal bases. These four steps aim to develop different skills by the students.

\section{METHODOLOGY TO DESIGN THE PROJECT}

A GCH2220 project is not something new for the course. Before the autumn semester of 2012, the project consisted for the students to perform a simplified life cycle assessment (LCA). Basically, they had to calculate the potential environmental impacts of a product considering its entire life cycle: from the raw materials extraction to the product's end of life using the LCA methodology. The project core was data searching and compilation to generate and then interpret results. As the course is linked to the chemical engineering department, a design/ecodesign component was missing in the project description. At the same time, i.e. winter semester of 2012, a complementary project had to be defined for a student in a special situation. This complementary project consisted in a critical review of LCA reports written by former students and in a decision-making based on the results presented in the reports. These two facts were the starting points for the elaboration of a new project. 
In order to elaborate the project, the important skills to evaluate during the course, and the project in particular, were set. They can be classed in technical vs. transversal aspects as shown by Table 1. Considering the technical aspects, they are the core of our graduate studies, as TAs we can also present and explain them. Considering the transversal aspects, we have no formation in most of the fields excepting our own personal experiences. In order to form students to develop these transversal skills, we had to seek for some advices.

Table 1:Technical and transversal aspects assessed during the project.

\begin{tabular}{|c|c|}
\hline $\begin{array}{l}\text { Technical } \\
\text { aspects }\end{array}$ & $\begin{array}{l}\text { - Global comprehension of the LCA } \\
\text { methodology; } \\
\text { - Analysing LCA results to propose } \\
\text { practical solutions to environmental } \\
\text { problems; } \\
\text { - Elementary redesign of an } \\
\text { industrial process. }\end{array}$ \\
\hline $\begin{array}{l}\text { Transversal } \\
\text { aspects }\end{array}$ & $\begin{array}{l}\text { - } \text { Critical assessment of a peer report; } \\
\text { - } \quad \text { Assessing the economic and social } \\
\text { impacts of an environmental redesign; } \\
\text { - Teamwork; } \\
\text { - Communicating the results in a } \\
\text { professional, technical but also } \\
\text { comprehensive way. }\end{array}$ \\
\hline
\end{tabular}

In previous sessions, some difficulties were met concerning the teamwork: in a 4-people team sometimes tensions appeared and students came to the lecturer or the TAs to find an answer to these tensions. In order to solve these problems, we invited the teams to discuss their tensions and find a way, on a case-by-case basis, to answer it. This process is often a long one. Furthermore, it's better to anticipate the problem than to adapt. To avoid these problems in multidisciplinary teams, we had a meeting with the person in charge of the Internal Relationships course given in Polytechnique. This person offered us tools and exercises to do during class in order to prevent teams' tensions.

Lectures, conferences and also a workshop given by the Polytechnique's pedagogic support office (Bureau d'appui pédagogique) were also followed to help to create a correct learning experience during class. It has been shown, for example, that teachers' encouragements to student are a key to success, as new methods of instruction require an adjustment period before optimal application [11]. A cooperative atmosphere needs to be created in the classroom, even though science courses are often competitive, to ensure students' participation in discussion [11]. This cooperative atmosphere can be reached by fostering teamwork and participatory learning during the classroom by proposing different kinds of activities and scheduling the classroom session around the different skills that are evaluated during the project (cf. Table 1).

A cooperative atmosphere can furthermore be created in the different work teams. It has been decided to build teams as diverse as possible according to the speciality and the amount of credits completed by each participant. This decision was based on the assumption that a diversity of people with different backgrounds can lead to discussions between the team members about how the project is perceived, and lead to concept's explanations among the members to support peer-learning.

\section{RESULTS}

The project proposed to students of winter semester of 2013 consisted in an environmental redesign of coated paper production in the Province of Quebec. The project aims: 1 . To give a teamwork experience in conducting a project including two reports and a poster presentation, 2 . To develop critical thinking when analyzing the results of an environmental assessment, 3. To elaborate an environmental redesign proposition for which the environmental gain is demonstrated and based on a recognized methodology, and 4. To develop skills to convince people within a company regarding the adoption of environmental solutions.

Teams of four students were created by TAs in order to promote peer-learning, as mentioned before, and to ensure equity between teams, as the classroom consisted of engineering students from different programs and with different amounts of credits completed. This way, new experiences in teamwork are guaranteed since students of the team don't already know each other and don't have the same engineering background.

Students' work was divided in three exercises: 1. A critical analysis based on technical aspects and formal aspects of an LCA report on coated paper production, 2. A technical report presenting the redesign proposed according to different criteria, the environmental evaluation based on a simplified LCA, the strengths and weaknesses according to the product quality, the socioeconomic consequences, and the product environmental performance, and steps to minimise negative consequences, and 3. A poster presentation aiming to convince people in a four minutes speech to finance the project proposed. While the first and second exercises were evaluated by the TAs, the poster presentation was evaluated by the TAs, the professor and the students from the half of the class that was not presenting at this period. Technical and soft skills were evaluated, as evaluations focused on technical knowledge, as well as on application of knowledge in a particular context, and understanding of project consequences on the society. Otherwise, the redesign proposal allowed students to demonstrate creativity and risk taking because no particular results were expected. The project, then, reflected more 
accurately the work of environmental engineers according to Clift's proposition [7].

Collaboration between teams was favoured by a student forum available online for the course students, TAs and professor. This contributed to the cooperative atmosphere in the classroom, important for peer learning [11]. During class, three periods of two hours were scheduled for the project. These periods aimed to explain each exercise expectations and their links with the professional reality, to review technical concepts needed for the exercises, and to discuss an exercise element with concrete examples with the students.

\section{LIMITS AND RECOMMENDATIONS}

Certain limits were observed during the semester. First of all, the project addresses key elements that aren't directly taught in different engineering classes but necessary for decision-makers, such as handling assumptions, scenarios building, uncertainties, and critical assessment, making them difficult for student to handle. Also, creativity and risk taking expectations are not adapted to first-year students often demonstrating a lack of self-confidence in a situation out of their comfort zone. The high level of diversity in the teams was expected to enhance knowledge transfer between more experimented and first-year students. This peer learning wasn't apparent from the reports. It may be caused by a lack of time or a lack of motivation.

The feedback from students regarding teamwork wasn't unanimous. Some students complained about the difficulties to schedule meetings in heterogeneous teams. Others mentioned the benefits of working with people from different engineering specialities.

More efforts should be made to simplify and clarify the scenarios studied and the amount of information given. The diversity of evaluation criteria and information well represents the complexity of engineering projects, but easily confuses students in a pedagogical context.

\section{CONCLUSION}

This project and its elaboration was also an opportunity for us, as TAs, to develop some new transversal skills too regarding teaching and communicating information. We had to make shifts in the way we explain LCA and the project depending on the situation: in front of the class or in front of one or two students. It was also a chance for us to test our vision of $\mathrm{SD}$ teaching in an engineering class and to assess how students respond to this vision.

The project, as it was presented here, is only two semesters old and must be considered as a work in progress, there is room for improvement in the way it is given regarding the different cited limits and the feedback given by students.

Finally, despite the difficulties for students to handle assumptions and uncertainties in projects and the lack of confidence characterizing younger students, we saw learning in the reports we corrected and we hope that the assumption "greatest accomplishments aren't possible in simple project" had been verified.

\section{Acknowledgments}

We want to thank all the students that took the class GCH2220 during the autumn 2012 and winter 2013 semesters and that tested this new kind of project for the class.

\section{REFERENCES}

[1] Desha, C. J., K. C. Hargroves, et al., "Adressing the time lag dilemma in curriculum renewal towards engineering education for sustainable development," International Journal of Sustainability in Higher Education, vol 10, no 2, pp. 184-199, 2009.

[2] Engineers Canada, "Engineering Education Accreditation in Canada," Presentation to the APEGA Council. Calgary, AB, 2012.

[3] Brundtland, G. H. and CMED, Notre avenir à tous, Commission Mondiale sur l'Environnement et le Développement (CMED), 1987.

[4] Lélé, S. M. "Sustainable Development: A Critical Review," World Development, vol 19, no 6, pp 607-621, 1991.

[5] Griggs, D., M. Stafford-Smith, et al., "Sustainable development goals for people and planet," Nature, vol 495, pp. 305-307, 2013.

[6] UNESCO, Education for Sustainable Development (ESD), 2012. Available as of April 17, 2013 from http://www.unesco.org/new/en/education/themes/leadingthe-international-agenda/education-for-sustainabledevelopment/

[7] Clift, R., "Engineering for the Environment: The New Model Engineer and her Role," Process Safety and Environmental Protection, vol 76, no 2, pp. 151-160, 1998.

[8] Gopakumar, G., D. Dysart-Gale, et al., "Models for leadership in curricular innovation: Concordia's centre for engineering in society", in Proc. CEEA Canadian Engineering Education Conf., CEEC12, (Winnipeg, MB; 17-20 June 2012), 6 pp., 2012.

[9] Engineers without borders, EWB-Canadian Ventures Engineers, 2013. Available as of April 24, 2013 from http://www.ewb.ca/canada/ 
[10] Kozanitis, A., L'évaluation du travail en équipe, Bureau d'appui pédagogique, Polytechnique Montreal, 2005.

[11] Crouch, C. H., J. F. Watkins, A.P., et al., "Peer Instruction: Engaging Students One-on-One, All at Once.", ResearchBased Reform of University Physics, vol 1, no 1, 55 pp., 2007.

[12] Mazur, E., "Éduquer les innovateurs du 21ème siècle", Presentation to the $11^{\text {th }}$ research day, Polytechnique Montreal, 2012. 